\title{
An Unparalleled Scientific Resource Endangered
}

\author{
J. G. Hering, ${ }^{* \dagger}$ D. L. Swackhamer, ${ }^{\ddagger}$ and W. H. Schlesinger ${ }^{\S}$ \\ ${ }^{\dagger}$ Eawag, Swiss Federal Institute of Aquatic Science and Technology, CH-8600 Dübendorf, Switzerland \\ ${ }^{\ddagger}$ Humphrey Institute of Public Affairs and Water Resources Center, University of Minnesota, Minneapolis, Minnesota 55455, \\ United States \\ ${ }^{\S}$ Cary Institute of Ecosystem Studies, Millbrook, New York 12545, United States
}

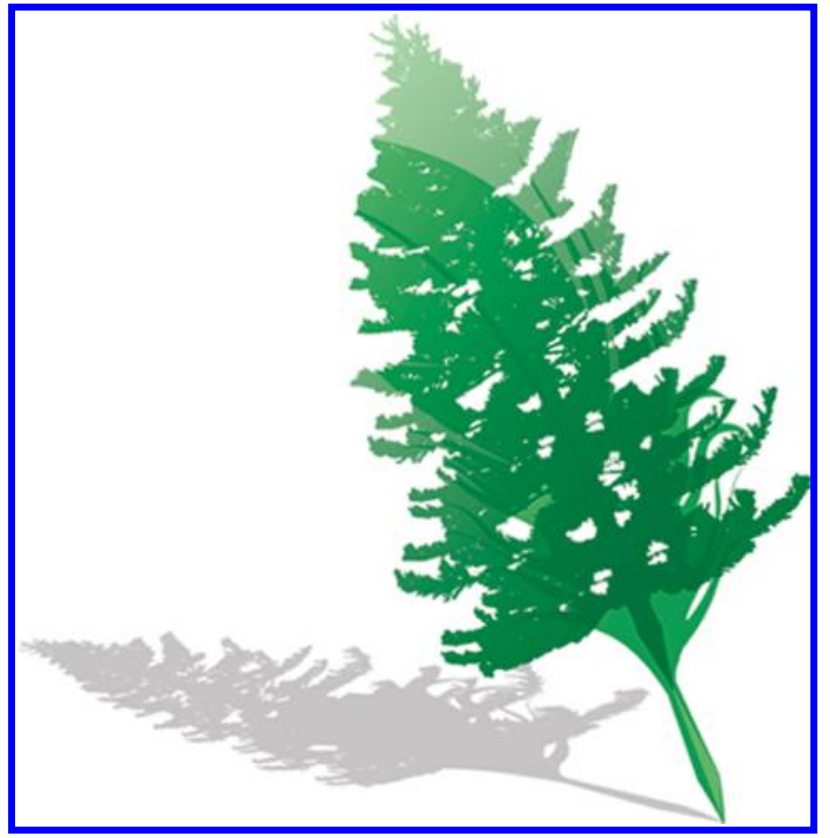

T early half a century ago, a unique resource for freshwater 1 research was created. The Experimental Lakes Area (ELA) consists of 58 lakes and their drainage basins in Ontario, Canada. The ELA was designed to allow whole-lake manipulation experiments; in addition, unperturbed ELA lakes have been monitored for the past 44 years. There is no other facility in the world that allows for the study of physical, chemical, and biological processes in whole-lake ecosystems at this order of magnitude. Now, this facility is under the threat of closure in 2013.

The planned closure of the ELA has inspired outspoken support from the scientific community (see: http://saveela.org/). It has also highlighted the importance of two central features of the ELA: ecosystem-scale experiments and long-term monitoring. These features have enabled the ELA to generate policy-relevant science that has had major impact on political decision-making in the environmental arena for nearly four decades.

Two classic examples of policy-relevant science at ELA are the studies of the roles of nitrogen and phosphorus in lake eutrophication ${ }^{1}$ and of the impacts of lake acidification on fish. ${ }^{2}$ The former study produced one of the truly iconic images in ecology (see Figure 1) and motivated legislative and regulatory measures to control phosphate inputs to inland and coastal waters. Results of the latter study motivated controls on smokestack emissions of sulfur dioxide across all of North America. More recently, the complete collapse of a fish

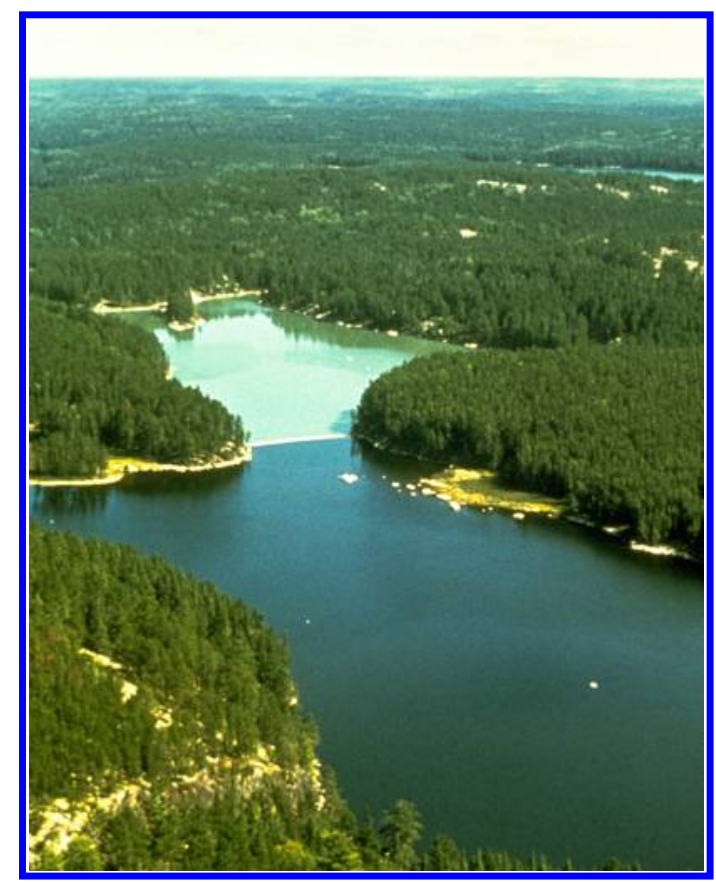

Figure 1. Whole lake eutrophication experiment conducted at ELA. ${ }^{1}$ Used with copyright permission from the American Association for the Advancement of Science.

population in response to exposure to artificial estrogen has been observed in a new experiment. ${ }^{3}$ An ongoing experiment on the whole-lake effects of nanosilver will be compromised if the closure proceeds as planned.

Whole-lake experiments produce more than just striking aerial photographs. They allow researchers to capture the effects of complex interactions across trophic levels and provide direct evidence of pollutant impacts on lakes without questionable extrapolation from small bottles to the ecosystem. This provides the robust results that are needed to justify significant expenditures of public funds for pollution control and mitigation.

Less well-known are the long-term records of physical, biological and chemical parameters that have been compiled for unperturbed ELA lakes. These consistent, long-term records are invaluable for the identification of environmental trends in an era of global climate change. As early as 1990, a signature of

Received: July 27, 2012

Accepted: July 30, 2012 
climatic warming was detected in data collected during the preceding two decades. ${ }^{5}$ It would be a huge loss- not only to science but to the scientific heritage of humanity-if this longterm monitoring activity were to be discontinued.

The scientific quality of the work conducted at the ELA is not in question. Research at ELA has generated almost 750 peer-reviewed publications, of which 19 appeared in Science or Nature. David Schindler's classic paper in Science ${ }^{1}$ has been cited over 300 times. An additional 31 papers appeared in this journal, Environmental Science \& Technology. More than 200 papers have appeared in the Canadian Journal of Fisheries and Aquatic Science. Canada's Office of the Auditor General has given the ELA outstanding reviews.

As recently as 2008, the status of the ELA was described as "secure". 4 The ELA faced the threat of closure in 1996 but was saved, in part due to the efforts of scientists and scientific societies. It is of critical importance that the current threat of closure in 2013 be averted. In a world facing unprecedented effects of global climate change, we can ill afford to abandon a facility that offers the unique combination of long-term monitoring and the capacity for ecosystem-scale experimentation.

\section{AUTHOR INFORMATION}

\section{Corresponding Author}

*E-mail: janet.hering@eawag.ch.

\section{Notes}

The authors declare no competing financial interest.

\section{REFERENCES}

(1) Schindler, D. W. Eutrophication and recovery in experimental lakes: implications for lake management. Science 1974, 184, 897-899.

(2) Schindler, D. W.; Mills, K. H.; Malley, D. F.; Findlay, D. L.; Shearer, J. A.; Davies, I. J.; Turner, M. A.; Linsey, G. A.; Cruikshank, D. R. Long-term ecosystem stress: The effects of years of acidification on a small lake. Science 1985, 228, 1395-1401.

(3) Kidd, K. A.; Blanchfield, P. J.; Mills, K. H.; Palace, V. P.; Evans, R. E.; Lazorchak, J. M.; Flick, R. W. Collapse of a fish population after exposure to a synthetic estrogen. Proc. Natl. Acad. Sci. U.S.A. 2007, 104, 8897-8901.

(4) Stokstad, E. Canada's experimental lakes. Science 2008, 322, 1316-1319.

(5) Schindler, D. W.; Beaty, K. G.; Fee, E. J.; Cruikshank, D. R.; DeBruyn, E. R.; Findlay, D. L.; Linsey, G. A.; Shearer, J. A.; Stainton, M. P.; Turner, M. A. Effects of climatic warming on lakes of the central boreal forest. Science 1990, 250, 967-970. 